\title{
The Effects of Coordination Trainings on Different Surfaces on the Slalom Downhill Speed Velocity of Snowboarders
}

\author{
Levent Tanyeri ${ }^{1}$, Sercan Öncen ${ }^{2}$ \\ ${ }^{1}$ School of Physical Education and Sports, Kafkas University, Kars, Turkey \\ ${ }^{2}$ School of Physical Education and Sports, Tekirdağ Namık Kemal University, Tekirdağ, Turkey \\ Correspondence: Levent Tanyeri, School of Physical Education and Sports, Kafkas University, 36500 Sarıkamış/KARS, \\ Turkey.
}

Received: January 6, 2019

doi:10.11114/jets.v7i3.4099
Accepted: February 25, 2019 Online Published: February 26, 2019

URL: https://doi.org/10.11114/jets.v7i3.4099

\begin{abstract}
Purpose: Snowboarding is a branch of sport, an individual Alpine sport, which requires superior physical structure. In snowboarding, snowboarders are expected to have high level aerobic and anaerobic strength to become successful. In the present study, the effects of training programs on different surfaces on slalom downhill speed of snowboarding-Alpine snowboarders were examined.

Methods: 18 male snowboarders in the Turkish National Snowboarding Alpine team participated in the study. Snowboarders were divided into two groups. Experimental group (G1) was divided into train on non-stable surface and stable surface groups. The experimental group got a coordination and classical snowboarding training program on different surfaces over 8 weeks for 2 days per week (Tuesday-Thursday). Stable surfaces were used on Tuesday and consisted of surfaces with Bosu ball, balance rope, plates ball, balance cushion, balance board, and balance disk. Non-stable surfaces were used on Wednesday and consisted foo skiing exercises that will disturb the balance of the sport player including straight slalom track, degrade surface track, skiing on hard surface, skiing on soft surface, skiing on one foot with eyes open, skiing with eyes closed. The control group (CG) received a classical training program. Trainings were scheduled to leave at least 36 hours between two application days. To determine the speed capacities of the snowboarders the slalom downhill speed test was used; to test agility, the hexagonal test was used, and to measure balance techno body prokin static and dynamic balance tests were used. In the data analysis, descriptive statistics were used. For comparative analysis, the Mann-Whitney U test was used and the significance level was selected as 0.05 .
\end{abstract}

Findings: The research results revealed that coordination trainings conducted on different surfaces for 8 weeks had a significant effect on slalom downhill speed of snowboarding-Alpine snowboarders.

Keywords: coordination, snowboarding-alpine, speed, consistency in velocity

\section{Introduction}

Positive developments in physical and certain physiological dimensions have been observed in individuals participating in sports regularly. Therefore, increasing the number of proper exercise programs can help individuals to complete their daily work in a comfortable way, increase their life quality, and thus, can increase the level of life enjoyment (Zorba, 2004). Snowboarding is a challenging sport completed on snow. Players compete individually. Snowboarding players should have a well-established physical structure. Compared to other snowboarders, they should have more flexible and active muscle structures. Snowboarders should develop general anaerobic resistance to achieve success. However, it is important to develop speed and changing direction skills as well as velocity. Due to the fast changing parkours in snowboarding, snowboarders should have strong heart and blood circulation systems. Additionally, in terms of power, snowboarders should have special jumping and throwing power, transfer power to legs and body in a fast way, joint mobility, and perfect balance (Sevim, 2007).

As in all sport branches, technological developments has been observed in snowboarding rapidly. With advanced technologies, various important innovations including new competition types, tracks, skiing techniques, snowboarding lengths, shapes, and materials have been seen. All of these advancements have been exciting and pleasing for snowboarding. Rapid developments and increasing demand for snowboarding will help this branch of sport to improve. 
Snowboarding requires discipline. Even the slightest mistakes cannot be tolerated. Therefore, it is an important element for everyone who is skiing to maintain performances for the health of their own and other snowboarders (Berg and Eiken, 2000). In sports, developed and enhanced motor competencies are the most important factors to distinguish a good player from other snowboarders. Especially in snowboarding, athletic skills of a player are among the most important factors for audience and enjoyment of watching the competition. To convert athletic skills of a sport player into enjoyment of watching the competition, physical and physiological needs should be identified. After that, training programs based on these needs should be applied. All these gains could be combined and reflected with technique and tactic (Sevim, 2007).

Performances and health of snowboarders are extremely important. Due to the basic structure of snowboarding, snowboarders need flexible and strong muscles. Using flexibility, jumping, and power properties at maximum level in snowboarding requires a good training program (Berg and Eiken, 2000). It is extremely important for snowboarders to pay attention especially to muscle powers. Snowboarding is an activity that requires very low and very high intensity contraction in leg muscles especially during turns. Especially due to the changes in knee and elbow flexions, it is important for snowboarders to have strong leg muscles (Olyaei et al., 2006). Muscle tiredness in snowboarders might lead to significant problems. Therefore, it is required to determine muscle tiredness and evaluated results related with muscle tiredness. Another important factor for snowboarders during exercise and competition is knee joint stabilisation. Joint stabilisation consists of static and dynamic stabilisation. Quadriceps is based on dynamic stabilisation of knee joint (Spring, 2002). Most of the physical activities cover loco motor movements such as speed, running, jumping, and walking. These movements generally require using main-joint extensor muscles of hip, knee, and ankle (Lepers et al., 2000; Rahnama et al., 2006).

In snowboarding, it is important to emphasize bodily active training done to develop motor properties. Most effective and efficient training programs should be based on using proper methods for physical form of individual and physical and physiological needs (Koc et al., 2000). The purpose of training programs applied on snowboarders in snowboarding discipline is to maximize physical and physiological efficiency (Gencay and Çoksevim, 2000). Increasing efficiency of a player and power related with this efficiency is the direct quantitative and qualitative result of this work in the training (Muniroglu et al., 2000). To achieve success, the sport player should have general and special resistance, static and dynamic power, and perfection in velocity, reaction talent, skill, and mobility. On the other, in addition to general resistance of skiing sport, with special resistance related with skiing sport, good condition is snowboarders is one of the mandatory elements of this sport (Kiyici, 2007). Similarly, in snowboarding, resistance and coordination are extremely important.

Trainings have a large contribution to determine required physical and physiological properties of snowboarders. With an effective and efficient training program, it is possible to obtain desired good results. Snowboarding is a sport branch predominant with especially its own dynamics and high intensity, consecutive movements in short period with physical and physiological tiredness (Sevim, 2007). Therefore, it is important to offer the most effective training program to a player. Balance power, agility, and skill sufficiency could be developed with various trainings. In this study, effects of proprioceptive and coordinative power training on stable and non-stable surfaces were investigated. Although there have been several research regarding the effect of proprioceptive and balance sufficiency on decreasing frequency of anterior cruciate ligament and ankle injuries on non-stable surfaces, there has been a limited number of research on the relationship between balance skill and sportive performance (Mcguine et al., 2000; Hrysomallis, 2011; Witmer, 2011). According to Anderson and Behm (2004), imbalance is caused by having insufficient power output to realise a movement. This was a result of increased balance responsibility while the main movement was made. It was indicated that by developing balance skill, ratio of fundamental movement muscles would decrease to provide body stabilisation. Thus, these muscles could contribute as driving power in activities such as jumping or running (Kean et al., 2006; Simek et al., 2007; Karacabey, 2013). Hoffman et al. (1995) argued that imbalances case increased in tiredness.

For snowboarding, speed is important. The speed of the sport player is proportional with power. Accordingly, powerful snowboarders may have insufficient power levels at the same time (Sevim, 1999). This is caused by low power using speeds. Power could only be converted into fast power with special and effective trainings. One of the most effective parts of this method is the trainings containing plyometric exercises (Bompa, 1998; Thompson et al., 2007). Similarly, this could help snowboarding players to be good at speed.

\section{Method}

18 male snowboarders in Turkish National Snowboarding Alpine Team participated in this study. Snowboarders were divided into two groups. Experimental group (G1) was divided to train on non-stable surface and stable surface. The experimental group got a coordination and classical snowboarding training program on different surfaced during 8 weeks for 2 days per week (Tuesday-Thursday). Stable surfaces were used on Tuesday and consisted of surfaces with Bosu ball, balance rope, plates ball, balance cushion, balance board, and balance disk. Non-stable surfaces were used on 
Wednesday and consisted foo skiing exercises that will disturb the balance of the sport player including straight slalom track, degrade surface track, skiing on hard surface, skiing on soft surface, skiing on one foot with eyes open, skiing with eyes closed. Control group (CG) was subjected to classical training program. Trainings were scheduled to leave at least 36 hours between two application days. To determine speed capacities of the snowboarders, the slalom downhill speed test was used; to test agility, the hexagonal test was used, and to measure balance technobody prokin static and dynamic balance tests were used. In the data analysis, descriptive statistics were used. For comparative analysis, the Mann-Whitney U test was used and significance level was selected as 0.05. In data analysis, descriptive statistics were used. For comparative analysis Mann-Whitney U test was used and significance level was selected as $\mathrm{p}<0.05$.

\section{Findings}

\section{Anthropometric Measurement Result Differences}

Table 1. Anthropometric Measurement Result of Trainings Made Under Different Learning Methods

\begin{tabular}{lllll}
\hline & & Mean & Mann-Whitney U & p \\
\hline Height & Pre-test & 171.80 & 0.000 & 1.000 \\
& Post-test & 171.80 & & \\
Weight & Pre-test & 68.10 & 0.226 & 0.824 \\
& Post-test & 67.90 & & \\
\hline
\end{tabular}

When anthropometric test results were investigated, it was determined that different learning methods had no significant changing effect on height and weight values ( $p>0.05)$. There was no effect of different learning methods on height and weight.

Table 2. Anthropometric Measurement Result of Classical Trainings

\begin{tabular}{lllll}
\hline & & Mean & Mann-Whitney U & p \\
\hline Height & Pre-test & 173 & 0.000 & 1.000 \\
& Post-test & 173 & & \\
Weight & Pre-test & 71.4 & 0.983 & 0.353 \\
& Post-test & 70.9 & &
\end{tabular}

When anthropometric test results were investigated, it was determined that classical trainings had no significant changing effect on height and weight values $(\mathrm{p}>0.05)$. There was no effect of classical trainings on height and weight.

Table 3. Comparison of Anthropometric Measurement Result of Groups

\begin{tabular}{llllll}
\hline & & Pre-test & \multicolumn{3}{l}{ Post-test } \\
& & Mann-Whitney U & $\mathbf{p}$ & Mann-Whitney U & p \\
Height & DLM-CT & 1.054 & 0.358 & 1.437 & 0.222 \\
Weight & DLM-CT & 1.583 & 0.185 & 1.288 & 0.266 \\
\hline
\end{tabular}

Note: DLM (Different Learning Methods), CT (Classical Training)

When anthropometric test results were investigated, there was no significant difference between pre-test results (p>0.05). Groups had similar skills before the study. However, there was no difference between post-test results after trainings ( $p>0.05$ ). Different learning method and classical training anthropometric test results were similar.

\section{Agility Measurement Results Differences}

Table 4. Hexagonal Training Test Measurement Result of Trainings Made Under Different Learning Methods

\begin{tabular}{lllll}
\hline & & Mean & Mann-Whitney U & p \\
\hline Right & Pre-test & 13.27 & 4.251 & 0.000 \\
& Post-test & 9.22 & & \\
Left & Pre-test & 13.00 & 4.381 & 0.000 \\
& Post-test & 8.87 & &
\end{tabular}

When hexagonal test results were investigated, it was determined that there was significant difference between different learning methods and right and left agility values $(\mathrm{p}<0.05)$. different learning methods had positive effects right and left agility. 
Table 5. Hexagonal Test Measurement Results of Classical Training Group

\begin{tabular}{lllll}
\hline & & Mean & Mann-Whitney U & p \\
\hline Right Foot & Pre-test & 10.48 & 3.681 & 0.000 \\
& Post-test & 9.90 & & \\
Left Foot & Pre-test & 10.35 & 3.792 & 0.000 \\
& Post-test & 9.94 & &
\end{tabular}

When hexagonal test results were investigated, it was determined that there was significant difference between classical training and right and left agility values $(\mathrm{p}<0.05)$. Classical training has positive effect on right foot and left foot.

Table 6. Comparison of Hexagonal Test Results of Groups

\begin{tabular}{llllll}
\hline & & Pre-test & & Post-test \\
\hline \multirow{2}{*}{ Right Foot } & DLM-CT & 0.302 & Mann-Whitney U & pann-Whitney U & p \\
Left Foot & DLM-CT & 0.838 & 0.796 & 5.621 & 0.000 \\
& & & 0.436 & 4.325 & 0.000 \\
\hline
\end{tabular}

Note: DLM (Different Learning Methods), CT (Classical Training)

When the hexagonal test results were investigated, there was no significant difference between pre-test results ( $\mathrm{p}>0.05$ ). Groups had similar skills before the study. When post-test results after the trainings were investigated, significant difference for all trainings was determined. When the averages were investigated, it was identified that different learning methods had higher difference. It was determined that different learning methods were successful for hexagonal levels.

\section{Balance Measurement Result Differences}

Table 7. Balance Value Training Test Measurement Result of Trainings Made Under Different Learning Methods

\begin{tabular}{|c|c|c|c|c|c|}
\hline & & & Mean & Mann-Whitney U & $\mathbf{p}$ \\
\hline DYNAMIC BALANCE & Anterior & Pre-test & 58.50 & 3.541 & 0.000 \\
\hline \multirow{5}{*}{ Y BALANCE } & & Post-test & 62.20 & & \\
\hline & Posteromedial & Pre-test & 66.20 & 4.251 & 0.000 \\
\hline & & Post-test & 72.80 & & \\
\hline & Posteromedial & Pre-test & 66.30 & 4.658 & 0.000 \\
\hline & & Post-test & 73.25 & & \\
\hline \multirow[t]{6}{*}{ STATIC BALANCE } & Right Balance & Pre-test & 71.84 & 3.954 & 0.000 \\
\hline & & Post-test & 103.89 & & \\
\hline & Left Balance & Pre-test & 74.44 & 3.867 & 0.000 \\
\hline & & Post-test & 106.61 & & \\
\hline & Total Balance Av. & Pre-test & 73.25 & 4.068 & 0.000 \\
\hline & & Post-test & 110.34 & & \\
\hline
\end{tabular}

When dynamic balance test results were investigated, it was determined that there was significant difference between different learning methods and dynamic balance values $(\mathrm{p}<0.05)$. Different learning methods had positive effects on dynamic balance. When static balance test results were investigated, it was determined that there was significant difference between different learning methods and static balance values $(\mathrm{p}<0.05)$. Different learning methods had positive effects on static balance. 
Table 8. Balance Value Test Measurement Results of Classical Training Group

\begin{tabular}{|c|c|c|c|c|c|}
\hline & & & Mean & $\begin{array}{l}\text { Mann-Whitney } \\
\text { U }\end{array}$ & $\mathbf{p}$ \\
\hline \multirow{2}{*}{$\begin{array}{l}\text { DYNAMIC } \\
\text { BALANCE }\end{array}$} & \multirow[t]{2}{*}{ Anterior } & Pre-test & 58.7 & \multirow[t]{2}{*}{1.635} & \multirow[t]{2}{*}{0.178} \\
\hline & & Post-test & 59.2 & & \\
\hline \multirow[t]{4}{*}{ Y BALANCE } & \multirow[t]{2}{*}{ Posteromedial } & Pre-test & 68.0 & \multirow[t]{2}{*}{1.292} & \multirow[t]{2}{*}{0.185} \\
\hline & & Post-test & 68.7 & & \\
\hline & \multirow[t]{2}{*}{ Posteromedial } & Pre-test & 62.1 & \multirow[t]{2}{*}{1.792} & \multirow[t]{2}{*}{0.113} \\
\hline & & Post-test & 62.9 & & \\
\hline \multirow{6}{*}{$\begin{array}{l}\text { STATIC } \\
\text { BALANCE }\end{array}$} & \multirow[t]{2}{*}{ Right Balance } & Pre-test & 74.50 & \multirow[t]{2}{*}{2.496} & \multirow[t]{2}{*}{0.011} \\
\hline & & Post-test & 101.19 & & \\
\hline & \multirow[t]{2}{*}{ Left Balance } & Pre-test & 80.20 & \multirow[t]{2}{*}{2.306} & \multirow[t]{2}{*}{0.019} \\
\hline & & Post-test & 101.82 & & \\
\hline & \multirow[t]{2}{*}{ Total Balance Av. } & Pre-test & 79.10 & \multirow[t]{2}{*}{3.553} & \multirow[t]{2}{*}{0.000} \\
\hline & & Post-test & 104.69 & & \\
\hline
\end{tabular}

When dynamic balance test results were investigated, it was determined that there was no significant difference between classical training and dynamic balance values ( $p>0.05$ ). Classical training had no effect on dynamic balance. When static balance test results were investigated, it was determined that there was a significant difference between classical training and static balance values $(\mathrm{p}<0.05)$. Classical training has positive effect on right, left and total balance values.

Table 9. Comparison of Balance Value Test Results of All Groups

\begin{tabular}{llllll}
\hline & & $\begin{array}{l}\text { Pre-test } \\
\text { Mann-Whitney U }\end{array}$ & $\mathbf{p}$ & $\begin{array}{l}\text { Post-test } \\
\text { Mann-Whitney U }\end{array}$ & $\mathbf{p}$ \\
\hline Anterior & DLM-CT & 1.561 & 0.235 & 3.681 & 0.000 \\
Posteromedial & DLM-CT & 1.821 & 0.139 & 4.648 & 0.000 \\
Posteromedial & DLM-CT & 0.712 & 0.458 & 3.896 & 0.000 \\
Right Balance & DLM-CT & 1.664 & 0.105 & 2.873 & 0.003 \\
Left Balance & DLM-CT & 1.965 & 0.052 & 3.441 & 0.000 \\
Total Balance Av. & DLM-CT & 0.872 & 0.381 & 3.628 & 0.000 \\
\hline
\end{tabular}

Note: DLM (Different Learning Methods), CT (Classical Training)

When balance test results were investigated, there was no significant difference between pre-test results ( $p>0.05)$. Groups had similar skills before the study. When post-test results after the trainings were investigated, significant difference between trainings was determined. When the averages were investigated, it was identified that different learning methods had higher difference. It was determined that different learning methods were successful for balance measurement.

\section{Speed Measurement Results Differences}

Table 10. Slalom downhill Measurement Results for Different Learning Methods

\begin{tabular}{lllll}
\hline \multirow{3}{*}{ Slalom downhill } & & Mean & Mann-Whitney U & $\mathbf{p}$ \\
& Pre-test & 53.85 & 3.690 & 0.000 \\
& Post-test & 45.46 & & \\
\hline
\end{tabular}

When speed and skill test results were investigated, it was determined that there was significant difference between different learning methods and $30 \mathrm{~m}$ speed and slalom downhill speed levels $(\mathrm{p}<0.05)$. Different learning methods had positive effect on 30m speed and slalom downhill speed levels.

Table 11. Slalom downhill Measurement Results for Classical Training

\begin{tabular}{lllll}
\hline & & Mean & Mann-Whitney U & p \\
\hline Slalom downhill & Pre-test & 53.22 & 3.863 & 0.000 \\
& Post-test & 50.65 & &
\end{tabular}

When speed and skill test results were investigated, it was determined that there was significant difference between classical training and $30 \mathrm{~m}$ speed and slalom downhill speed levels $(\mathrm{p}<0.05)$. Classical training had positive effect on $30 \mathrm{~m}$ speed and slalom downhill speed levels. 
Table 12. Comparison of Slalom Downhill Results of Groups

\begin{tabular}{lcllll}
\hline & & Pre-test & & Post-test \\
Mann-Whitney U & $\mathbf{p}$ & Mann-Whitney $\mathbf{U}$ & p \\
Slalom downhill & DLM-CT & 0.608 & 0.579 & 5.324 & 0.000 \\
\hline
\end{tabular}

Note: DLM (Different Learning Methods), CT (Classical Training)

When speed and skill test results were investigated, there was no significant difference between pre-test results ( $p>0.05$ ). Groups had similar skills before the study. When post-test results after the trainings were investigated, significant difference for all trainings was determined. When the averages were investigated, it was identified that different learning methods had higher difference. It was determined that different learning methods were successful for slalom downhill levels.

\section{Discussion}

Due to the structure of snowboarding, it is a pre-requisite that snowboarders need flexible and powerful muscles and use flexibility, jumping, and power properties at maximum level. Development of these properties of snowboarders could be achieved with good training. In this study, effects of different learning methods and classical training on snowboarding players were investigated and compared. In this study, it was determined that different learning methods were more successful for agility, balance, and speed levels compared to classical trainings. Using different learning methods in snowboarding training has positive effects on agility, balance, and speed levels of snowboarders. Schöllhorn and Bauer (1998) determined that javelin throwers had experienced positive effects when these snowboarders used different learning methods. Erkmen et al. (2007) conducted a study to investigate effects of classical training on balance vales and identified that these trainings had no effect on balance values. However, Holm et. (2004) found that classical training that is applied to prevent injury had also developed dynamic balance. Irang, Whitney and Cox (2004) stated that standard stretching exercise had increased dynamic and static balance levels of snowboarders before competition, yet, as sportive performance is linked with various factors, there were no precise results. Behm et al. (2001) determined that classical trainings that are commonly applied had effect on agility of bicepsphemoris and vastuslateralis muscle groups. Fadhloun, Chelly and Bensbaa (2011) applied standard trainings on 20 young handball players and identified that agility and active jumping levels of these players significantly improved. Stoggl et al. (2007) stated that trainings in ski sport on non-stable surfaced had effects on speed. Similarly, Vesterinen et al. (2009) stated that training on non-stable surface had effects on ski degrees. As a result, it was determined that trainings in this study had effects on snowboarding skills, however, the level of the effect showed differences. While different learning methods had larger effects on snowboarding skills, effects of classical trainings are lower. It is possible to state that different learning methods are among successful training programs that help increasing skills of snowboarders.

\section{References}

Anderson, K. G., \& Behm, D. G. (2004). Maintenance of EMG Activity and Loss of Force Output with Instability, The Journal of Strength \& Conditioning Research, 18(3), 637-640.

Behm, D., Button, D., \& Butt, J. (2001). Factors Affecting Force Loss With Prolonged Stretching, Canadian Journal of Applied Physiology, 126(3), 261-272. https://doi.org/10.1139/h01-017

Berg, H. E., \& Eiken, O. (2000). Muscle control in elite alpine skiing. Med Sci Sport Exerc., 31, 1065-7.

Bompa, T. O. (1998). Training Theory and Method, Bagirgan Press, Ankara.

Erkmen, N., Suveren, S., Yazicioglu, K., \& Goktepe, A. S. (2007). Comparison of Balance Performance of Athletes in Different Branches of Sports, Spormeter, Journal of Physical Education and Sport Sciences, 3, 115-122.

Fadhloun, M., Chelly, M. S., \& Bensbaa, A. (2011). Relationship between Agility T-test and Physical Fitness Measures as Indicators of Performance in Elite Adolescent Handball Players. проблеми фізичного виховання і спорту.

Gencay, O. A., \& Coksevim, B. (2000). Evaluation of Athletic Performance of Professional Football Players during Preparatory Periods, $1^{\text {st }}$ Congress of Physical Education and Sport Sciences in Gazi University, 87-93. https://doi.org/10.2519/jospt.1995.21.2.90

Guskiew1chz, K. M. (2004). Regaining Postural Stability and Balance, "Rehabilitation Techniques for Sports Prentice Medicine and Athletıc Training”, (Ed. Prentice.W.E.), McGraw Hill Companies, Fourth Edition, New York.

Hoffman, M., \& Payne, V. G. (1995). The Effects of Proprioceptive Ankle Disk Training on Healthy Subjects, The Journal of Orthopaedic and Sports Physical Therapy, 21(2), 90-93.

Holm, I., Fosdahl, M. A., Frı1s, A., Risberg, M. A., Myklebust, G., \& Haraldsteen, H. (2004). Effect of Neuromuscular Training on Proprioception, Balance, Muscle Strength and Lower Limb Function in Female Team Handball Players. Clin J Sport Med, 14, 88-94. https://doi.org/10.1097/00042752-200403000-00006 
Hrysomallis, C. (2011). Balance Ability and Athletic Performance, Review Article, Sports Medicine, 41(3), 221-232,

Karacabey, K. (2013). Performance and Agility Tests in Sports, International Journal of Human Sciences, 10(1), 1693-1704. https://doi.org/10.2165/11538560-000000000-00000

Kean, C. O., Behm, D. G., \& Young, W. B. (2006). Fixed Foot Balance Training Increases Rectus Femoris Activation During Landing and Jump Height in Recreationally Active Women, Journal of Sports Sciences Medicine, 5(1), $138-148$.

Kiyici, F. (2007). Investigation of Levels of Serum Superoxide, Dismutase Catalase and Meloaldehit after Velocity Exercises in Alpine Skiing. Master Thesis.

Koc, H., Gokdemir, K., \& Kilinc, F. (2000). Effects of Seasonal Exercises on Some Physical and Physiological Parameters of Football Players of Kütahyaspor, $1^{\text {st }}$ Congress of Physical Education and Sport Sciences in Gazi University., 122-128.

Lepers, R., Pousson, M., Maffiuletti, N., Martin, A., \& Van Hoecke, J. (2000). The effects of a prolonged running exercise on strength characteristics. International Journal of Sports Medicine, 21, 275-280. https://doi.org/10.1055/s-2000-308

Mcguine, T. A., Greene, J. J., Best, T., \& Leverson, G. (2000). Balance as a Predictor of Ankle Injuries in High School Basketball Players, Clinical of Journal Sports Medicine, 10(4), 239-244. https://doi.org/10.1097/00042752-200010000-00003

Muniroglu, S., Koz, M., Atil, M., Erongun, D., \& Bulca, Y. S. (2000). Pre and Post-Season Investigation of Physical and Physiological Characteristics of a Soccer Team Playing In the First Professional League of. $1^{\text {st }}$ Congress of Physical Education and Sport Sciences in Gazi University, Congress Book, 103-106.

Olyaeı, G. R., Hadıon, M. R., Talebıan, S., Bagherı, H., Malmır, K., \& Olyaeı, M. (2006). The Effect Of Muscle Fatigue On Knee Flexor To Extensor Torque Ratios And Knee.

Rahnama, N., Lees, A., \& Reilly, T. (2006). Electromyography of selected lower-limb muscles fatigued by exercise at the intensity of soccer match-play. Journal of Electromyography and Kinesiology, 16(3), 257-263. https://doi.org/10.1016/j.jelekin.2005.07.011

Schöllhorn, W. I., \& Bauer, H. U. (1998). Identifying individual movement styles in high performance sports by means of self-organizing kohonen maps. In ISBS-Conference Proceedings Archive, 1(1), 1-5.

Sevim, Y. (1999). Training Information Course Notes. Ankara. Prerequisites for Selection of Talents

Sevim, Y. (2007). Training Information. Edition Number 358. Ankara: Nobel Press.

Simek, S. S., Milanovic, D., \& Jukic, I. (2007). The Effects of Proprioceptive Training on Jumping and Agility Performance, Kinesiol, 39(2), 131-41.

Spring, V. (2002). Cross Country Ski Trials in Washington. Third Edition ed., The Mountaineers Books, USA

Stoggl, T., Lindinger, S., \& Muller, E. (2007). Analysis of a Simulated Sprint Competition in Classical Cross Country Skiing. Scandinavian Journal of Medicine \& Science in Sports, 17(4), 362-372.

Thompson, A. M., Micus, C. R., \& Rodarte, R. Q. at al., (2007). Inflammation and exercise (INFLAME): Study rationale, design, and methods, Contemporary Clinical Trials; 254, 0-10

Vesterinen, V., Mikkola, J., Nummela, A., Hynynen, E., \& Hakkinen, K., (2009). Fatigue in a Simulated Cross-Country Skiing Sprint Competition, Journal of Sports Sciences, 27(10), 1069-1077. https://doi.org/10.1080/02640410903081860

Witmer, C. A., Oberacker, L. M., Moir, G. L., Davis, S. E., \& Haff, G. G. (2011). The Effects of Stable versus Unstable Surface Resistance Training on Performance of Female Soccer Players, Medicine and Science in Sports and Exercise, 43(5), 839. https://doi.org/10.1249/01.MSS.0000402339.03630.ab

Zorba, E. (2004). The Effect of 10 Week Training Program on Some Physical Fitness Parameters in Elderly People between the Ages of 65 and 85, Firat University Journal of Health Sciences, 18(4), 229-234.

\section{Copyrights}

Copyright for this article is retained by the author(s), with first publication rights granted to the journal.

This is an open-access article distributed under the terms and conditions of the Creative Commons Attribution license which permits unrestricted use, distribution, and reproduction in any medium, provided the original work is properly cited. 